\title{
Isolation of DNA from archival Papanicolaou stained cytological smears using a simple salting-out procedure
}

\author{
M Poljak, J Barlič, K Seme, T Avšič-Županc, A Zore
}

\begin{abstract}
DNA from archival Papanicolaou stained and unstained cytological smears was successfully isolated using a simple, rapid and inexpensive salting-out procedure. The quality of DNA was controlled by polymerase chain reaction (PCR) amplification of segments of the human $\beta$-globin, human $\beta$-actin and human papillomavirus L1 genes. Only negligible differences in amplification efficiency were observed between DNA isolated from stained and unstained smears. The salting-out procedure is a more rapid method for the isolation of DNA than phenolchloroform extraction and may be used in instances where fresh or cryopreserved clinical specimens are not available. (f Clin Pathol: Mol Pathol 1995;48:M55-M56)
\end{abstract}

Keywords: Polymerase chain reaction, DNA isolation.

Recent introduction of the polymerase chain reaction (PCR) has stimulated interest in the use of archival clinical specimens for molecular analyses. Common archival clinical material in pathology laboratories includes Papanicolaou stained glass slide smears. Methods for successful isolation of DNA from this material have been reported previously. ${ }^{12}$ However, cumbersome and laborious procedures with the hazardous organic solvents phenol and chloroform are necessary for this purpose. Here, we describe a simple, rapid and inexpensive procedure for the isolation of DNA from archival Papanicolaou stained smears, permitting efficient PCR amplification.

Microbiology, Med Faculty of Ljubljana,

Zaloška 4, 61105

Ljubljana, Slovenia

M Poljak

$\mathrm{J}$ Barlič

K Seme

T Avšič-Županc

Department of Gynaecology, Medical Center Ljubljana, Šlajmerjeva 2, 61105 Ljubljana, Slovenia A Zore

Correspondence to: Dr M Poljak.

Accepted for publication 25 August 1994
DNA was isolated simultaneously from $\mathrm{Pa}$ panicolaou stained and unstained archival smears from the same patient. Two different procedures for DNA isolation were used. In the first procedure extraction of DNA was accomplished using the phenol/chloroform/ isoamyl alcohol protocol as described by Gall et al. ${ }^{1}$ In the second the coverslips were removed by boiling, and smears were then washed twice with xylene (30 minutes) and three times in absolute ethanol (five minutes). The dried smears were then scraped into a sterile Eppendorf tube using a new razor blade and incubated at $56^{\circ} \mathrm{C}$ for two hours in $150 \mu \mathrm{l}$ digestion buffer $(50 \mathrm{mM}$ Tris- $\mathrm{HCl}, 1 \mathrm{mM}$ EDTA, $1 \%$ Tween $20,1 \%$ Nonidet P-40) containing $800 \mu \mathrm{g} / \mathrm{ml}$ proteinase $\mathrm{K}$. Proteins were removed using a modified previously described method $^{4}: 60 \mu$ l saturated $\mathrm{NaCl}$ (approximately $6 \mathrm{M}$ ) were added to each tube and shaken vigorously for one minute, followed by centrifugation at $3000 \times g$ for 20 minutes. Supernatant containing DNA was transferred to another Eppendorf tube, and the DNA was precipitated with two volumes of absolute ethanol at $-20^{\circ} \mathrm{C}$ for 40 minutes. Samples were then centrifuged for 10 minutes at $6000 \times g$, the precipitate was air-dried and dissolved in $20 \mu \mathrm{l}$ TE buffer ( $10 \mathrm{mM}$ Tris- $\mathrm{HCl}, 0.2 \mathrm{mM}$ EDTA, pH 7.4).

The quality of DNA preparation was checked by amplification of segments of the human $\beta$ globin gene ( 268 base pairs), using the $\mathrm{GH} 20$ (5'-GAAGAGCCAAGGACAGGTAC-3') and PC04 (5'-CAACTTCATCCACGTTCACC$\left.3^{\prime}\right)$ primers, and the human $\beta$-actin gene ( 317 base pairs), using primers $5^{\prime}$-ATCATGTTTGAGACCTTCAACACCCC-3' and 5'-CATCTCTTGCTCGAAGTCCAGGGCGA-3' ${ }^{\prime}{ }^{5}$ Briefly, $2 \mu$ of DNA sample were added to a $100 \mu \mathrm{l}$ reaction mixture containing $200 \mu \mathrm{m} / 1$ each deoxynucleotide triphosphate, $10 \mathrm{mmol} / 1$ TRIS- $\mathrm{HCl}$ (pH 8.5), $50 \mathrm{mmol} / 1$ potassium chloride and $4 \mathrm{mmol} / \mathrm{l}$ magnesium chloride, 50 pmol primers, and 2.5 units of Taq polymerase (Perkin-Elmer Cetus Corporation, Norwalk, Connecticut, USA). The PCR mixture was overlaid with paraffin oil and subjected to 40 amplification cycles using a DNA Thermal Cycler 480 (Perkin-Elmer Cetus Instruments Corporation). Each cycle comprised one minute of denaturation at $95^{\circ} \mathrm{C}$, one minute of annealing at $55^{\circ} \mathrm{C}(\beta$-globin) or at $58^{\circ} \mathrm{C}$ ( $\beta$-actin), and two minutes of extension at $72^{\circ} \mathrm{C}$. Amplification products (one tenth of 


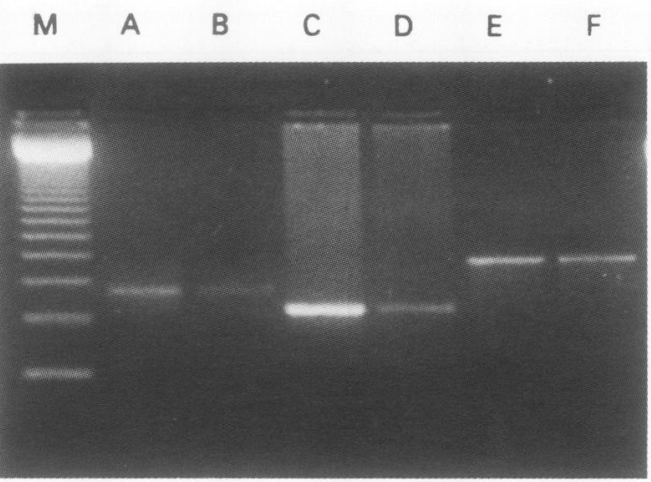

B
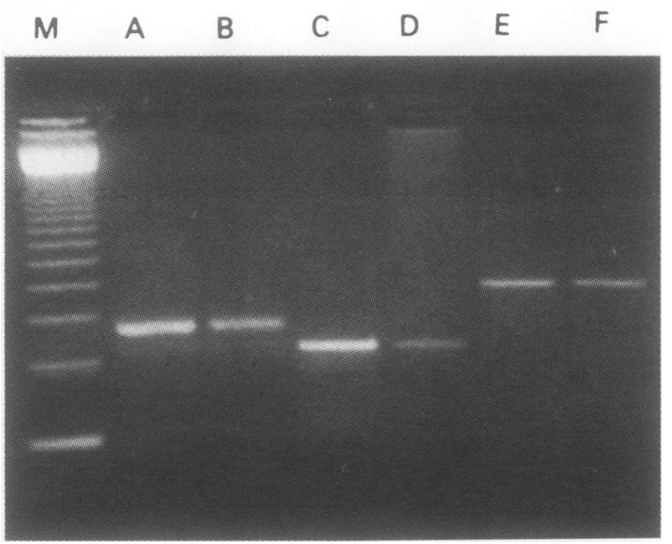

Comparison of DNA from Papanicolaou stained and unstained cervical smears obtained from a patient with a CIN II lesion using the salting-out $(A)$ and the phenol/ chloroform/isoamyl alcohol (B) methods. Agarose gel analysis of PCR amplified 317 base pair fragments of the human $\beta$-actin gene (lanes $A$ and $B$ ), 268 base pair fragments of the human $\beta$-globin gene (lanes $C$ and $D$ ) and of the 450 base pair fragments of the HPV L1 gene (lanes $E$ and $F$ ). Lane $M, 123$ base pair DNA ladder (Gibco-BRL): lanes $A, C$ and $E, \beta$-actin, $\beta$-globin and $H P V L 1$, respectively, from archival unstained smears; lanes $B, D$ and $F, \beta$-actin, $\beta$-globin and $H P V L 1$, respectively, from archival Papanicolaou stained smears.

the reaction) were separated by electrophoresis using a $3 \%$ agarose gel prepared with $0.5 \times \mathrm{TBE}$ buffer and were visualised by ultraviolet illumination following ethidium bromide staining.

\section{Results}

Only negligible differences in amplification efficiency were observed between Papanicolaou stained and unstained smears from the same patient (figure). Similarly, no important differences were found in the quality of DNA prepared using the phenol/chloroform/isoamyl alcohol method or the salting-out method (figure).

Additionally, a 450 base pair portion of the human papillomavirus (HPV) L1 region was successfully amplified, using commercially available MY09 and MY11 HPV L1 primers (Perkin Elmer, USA) according to a previously described method, ${ }^{5}$ from a few Papanicolaou stained and unstained cervical smears obtained from patients with cervical high grade squamous intraepithelial lesions (CIN II and III) (figure). To confirm the specificity of PCR products and determine the HPV type, the PCR products were digested with seven restriction endonucleases and analysed by agarose gel electrophoresis. ${ }^{5}$ The restriction enzyme digestion patterns were found to be unique mainly for HPV type 16 and in one case for HPV type 53 (data not shown).

\section{Discussion}

Diagnosis and classification of premalignant and malignant changes in the cervix are based mainly on cytological examination of $\mathrm{Pa}$ panicolaou stained smears. DNA was successfully isolated from archival Papanicolaou stained cervical smears using a modified phenol/chloroform/isoamyl alcohol method. ${ }^{12}$ Our results demonstrate that DNA suitable for PCR amplification can be obtained from archival stained smears using a simple and inexpensive salting-out procedure. This procedure was originally described for extraction of DNA from human nucleated blood cells. ${ }^{4}$ It has also been successfully used for the isolation of DNA from unstained archival bone marrow slides. ${ }^{6}$ To our knowledge, however, isolation of DNA from stained archival slides using a salting-out method has not been reported before.

Human papillomavirus are intimately linked with squamous cell neoplasms of the lower genital tract in both men and women. Thus, development of methods for simple detection of HPV infection has a central role in many strategies designed to reduce the risk of cervical neoplasms. ${ }^{7}$ We hope that the method described in this paper for the rapid detection of HPV infection in archival Papanicolaou stained cervical smears will contribute to these efforts.

In conclusion, we isolated DNA suitable for PCR amplification from Papanicolaou stained cervical smears using a simple salting-out procedure. We consider that this procedure is useful for retrospective and clinical correlative studies as well as for routine clinical diagnosis when fresh or cryopreserved specimens are not available.

1 Gall K, Pavičić D, Pavelić J, Audy-Jurković S, Pavelić K. PCR amplification of DNA from stained cytological smears. f Clin Pathol 1993;46:378-9.

2 Jakson DP, Bell S, Payne J, Lewis FA, Sutton J, Taylor GR, et al. Extraction and amplification of DNA from archival haematoxylin and eosin sections and cervical cytology $\mathrm{Pa}$ panicolaou smears. Nucleic Acids Res 1989;17:10134.

3 Smolka H, Soost HJ. An outline and atlas of gynaecological cytodiagnosis. London: Edward Arnold, 1965:11-12.

4 Miller SA, Dykes DD, Polesky HF. A simple salting out procedure for extracting DNA from human nucleated cells. procedure for extracting DNA from

5 Poljak M, Cerar A. Human papillomavirus type 16 DNA in oesophageal squamous cell carcinoma. Anticancer Res 1993;13:2113-16.

6 Roman J, Andres P, Alvarez MA, Torres A. Salting-out procedure for isolation of DNA from stored bone marrow procedure for isolation of DNA from stored bone
slides for PCR. Eur $\mathcal{F}$ Haematol 1993;50:237-8.

7 Crum CP. Genital papillomaviruses and related neoplasms: caution, diagnosis and classification. Mod Pathol 1994;7 138-45. 